\section{Çevre Mühendisliği /Environmental Engineering}

Araştırma Makalesi / Research Article

Geliş tarihi / Received: 06-09-2020
ISSN: 2146-0574, eISSN: 2536-4618 DOI: 10.21597/jist.791151

Kabul tarihi / Accepted: 22-01-2021

Atıf İçin: Gümüş D, Gümüş F, 2021. Taguchi Deneysel Tasarım Yöntemi Kullanılarak Bromfenol Mavisi Biyosorpsiyonunun Modellenmesi ve Denge İzotermleri. Iğdır Üniversitesi Fen Bilimleri Enstitüsü Dergisi, 11(2): 960-968.

To Cite: Gümüş D, Gümüş F, 2021. Modeling of Bromphenol Blue Biosorption Using Taguchi Experimental Design Method and Equilibrium Isotherms. Journal of the Institute of Science and Technology, 11(2): 960-968.

\title{
Taguchi Deneysel Tasarım Yöntemi Kullanılarak Bromfenol Mavisi Biyosorpsiyonunun Modellenmesi ve Denge
} İzotermleri

\section{Dilek GÜMÜŞ ${ }^{*}$, Fatih GÜMÜŞ²}

ÖZET: Su ortamında boyaların varlığı, ekosistem kalitesini olumsuz etkilediği için küresel bir sorundur. Tehlikeli boyaların biyosorpsiyon yöntemiyle ayrılması düşük maliyetli ve etkili bir yöntem olarak kullanılmaktadır. Bu çalışmada Fomes fomentarius (L.) Fr. ve Trametes versicolor (L.) Lloyd biyosorbent olarak kullanılarak sulu çözeltiden Bromfenol Mavisinin giderimi çalışılmışıtır. Taguchi deney tasarımında $\mathrm{L}_{9}\left(3^{3}\right)$ ortogonal dizi $(\mathrm{OD})$ kullanılarak başlangıç pH değeri $(2,7,12)$ başlangıç boya konsantrasyonu $\left(25,50,75 \mathrm{mg} \mathrm{L}^{-1}\right)$ ve temas süresi gibi $(30,150,270 \mathrm{dk})$ kontrol edilebilir 3 faktör ve her faktörün 3 farklı seviyesinin biyosorpsiyon sürecindeki istatistiksel ilişkileri araştırılmış ve sistemin optimizasyonu yapılmıştır. Deneysel çalışmalar sonucunda parametrelerin optimum değerleri $F$. fomentarius ile biyosorpsiyonda temas süresi $270 \mathrm{dk}$, başlangıç $\mathrm{pH}$ değeri 2 ve başlangıç boya konsantrasyonu $50 \mathrm{mg} \mathrm{L}^{-1}, T$. versicolor ile biyosorpsiyonda temas süresi $150 \mathrm{dk}$, başlangıç $\mathrm{pH}$ değeri 2 ve başlangıç boya konsantrasyonu $50 \mathrm{mg} \mathrm{L}^{-1}$ olarak belirlenmiştir. Belirlenen optimum koşullardaki boya giderim verimleri $F$. fomentarius için \%78.34, T. versicolor için \%69.28 olarak bulunmuştur. Biyosorpsiyon izotermleri Langmuir ve Freundlich denklemleri kullanılarak modellenmiştir. $F$. fomentarius ile yapılan deneylerde en iyi model uyumu Freundlich izotermi ile T. versicolor ile yapilan deneylerde en iyi uyum Langmuir izotermi ile sağlanmıştır. Giderim performansları göz önünde bulundurulduğunda her iki biyosorbentin de boya endüstrisi atıksularının gideriminde düşük maliyetli ve etkili biyosorbentler olarak değerlendirilebilecekleri sonucuna varılmıştır.

Anahtar Kelimeler: Biyosorpsiyon, Bromfenol Mavisi, Fomes fomentarius, deney tasarımı, doğrusal olmayan izoterm, Trametes versicolor.

Modeling of Bromphenol Blue Biosorption Using Taguchi Experimental Design Method and Equilibrium Isotherms

ABSTRACT: The presence of dyes in the aquatic environment is a global problem because of the negative consequences on the ecosystem quality. Adsorption process is used as a low cost and effective method for removing hazardous dyes. This study investigated removal of Bromophenol Blue from aqueous solutions by Fomes fomentarius and Trametes versicolor. The statistical relationships of the parameters in the biosorption process by considering three controllable factors including initial $\mathrm{pH}$ value $(2,7,12)$, initial dye concentration $\left(25,50,75 \mathrm{mg} \mathrm{L}^{-1}\right)$ and contact time $(30,150,270$ minutes) were investigated at three different levels and the biosorption process was optimized using Taguchi orthogonal array ( $\left.\mathrm{L}_{9} \mathrm{OA}\right)$ experimental design. As a result of experimental studies, the optimal dye removal conditions were determined as the contact time of 270 minutes, $\mathrm{pH}: 2$ and initial Bromophenol Blue concentration of $50 \mathrm{mg} \mathrm{L}^{-1}$ for $F$. fomentarius. The optimal dye removal conditions were determined as the contact time of 150 minutes, $\mathrm{pH}: 2$ and initial Bromophenol Blue concentration of $50 \mathrm{mg} \mathrm{L}^{-1}$ for $T$. versicolor. For F. fomentarius and T. versicolor, the removal efficiencies at optimum conditions were 78.34\% and $69.28 \%$, respectively. Biosorption isotherms were modeled using the Langmuir and Freundlich models. The biosorption of Bromephenol Blue on F. fomentarius and T. versicolor fitted better in the Freundlich and Langmuir models by non-linearized equations, respectively. Both biosorbents can be promising for dyes removal from aqueous environment.

Keywords: Biosorption, Bromophenol Blue, Fomes fomentarius, experimental design, non-linear isotherm, Trametes versicolor.

${ }^{1}$ Dilek GÜMÜŞ (Orcid ID: : 0000-0001-7665-3057), Sinop Üniversitesi, Yapı İşleri ve Teknik Daire Başkanlığı, 57010 Sinop-Türkiye ${ }^{2}$ Fatih GÜMÜŞ (Orcid ID: 0000-0002-4660-7591), Sinop Üniversitesi, Fen Edebiyat Fakültesi Bbiyoloji Bölümü,Sinop-Türkiye

*Sorumlu Yazar/Corresponding Author: Dilek GÜMÜŞ, e-mail: dilek.gumus@gmail.com 


\section{GİRiş}

Canlı yaşamı için hayati öneme sahip su kaynakları çeşitli endüstrilerin zararlı kimyasal atıklarını uygun şekilde bertaraf etmemesi neticesinde hızla kirlenmekte ve küresel çapta oluşacak su krizlerine de zemin hazırlamaktadır (Zare ve ark., 2018). Bu endüstriler arasında ticari boya kullanan tekstil, deri, kozmetik, gıda, baskı ve kağıt endüstrileri de yer almakta ve 100 000'den fazla ticari boya türü içeren renkli atıksu alıcı ortama deşarj edilmektedir (Katheresan ve ark., 2018). Boya endüstrisi atıksuları canlı organizmalar üzerindeki toksik etkilerinin yanı sıra çok düşük konsantrasyonlarda bile güneş 1şığı ve oksijen girişini engelleyerek sucul sistemlerin fotosentetik faaliyetleri üzerinde ciddi hasara neden olabilmektedir. Üstelik boyalar karmaşık kimyasal yapılarından dolayı bulundukları ortamda stabilitelerini uzun süre koruyabilmektedirler (El-Gamal ve ark., 2015). Tüm bunlardan dolayı boya kullanan endüstrilerin atıksularını deşarj etmeden önce renklendirici maddeleri elimine etmeleri son derece önemlidir.

Boya endüstrisi atıksularının arıtılmasında adsopsiyon, elektrokoagülasyon, membran filtrasyon, fotodegradasyon, ozonlama gibi birçok yöntem önerilmiştir (Seow ve Lim, 2016). Ancak tüm bu yöntemlerin çoğu maliyetli ve pratikte uygulanabilirlikleri sınırlıdır. Bu noktada adsorpsiyon işlemleri tasarım ve kullanım kolaylıklarının yanı sıra farklı karakterdeki boyaların giderimine elverişli olmaları ve nispeten daha düşük maliyetleri nedeniyle tercih sebebi olmuştur. Bu bağlamda sürdürülebilir ve doğa dostu biyosorbent araştırmaları halen popülerliğini yitirmemiştir.

$\mathrm{Bu}$ çalışmada biyosorbent olarak Fomes fomentarius ve Trametes versicolor makro mantarları kullanılarak başta tekstil endüstrisi olmak üzere birçok endüstride sıklıkla kullanılan bir boya türü olan Bromfenol Mavisi giderimi çalışılmıştır. Yerel olarak elde edilebilen mantar atıklarının doğal haliyle kullanılabilmesi, ucuz ve bol bulunabilir olması hem maliyet hem de sürdürülebilirlik açısından bir avantaj olarak görülmüş ve alternatif bir biyosorbent olabilecekleri girişimiyle araştırma yapılmıştır. Literatürde daha önce $F$. fomentarius ile Metilen Mavisi ve Rhodamine B boyalariyla (Maurya ve ark., 2006) T. versicolor ile kadmiyum, kurşun gibi çeşitli ağır metaller ve boyalarla ilgili biyosorpsiyon çalışmaları yapılmış (Subbaiah ve ark., 2011) ancak Bromfenol Mavisi ile bu kapsamda bir çalışma yapılmamıştır.

Çalışmada $\mathrm{pH}$, biyosorpsiyon süresi ve kirletici konsantrasyonu gibi en önemli parametrelerin giderim verimi üzerine etkileri araştırılmış ve Taguchi deneysel tasarım metodu kullanılarak proses optimizasyonu sağlanmıştır. İstatistiksel tekniklere dayanan deney tasarım yöntemlerinin kullanımının, sağlam tasarım çözümleri sunmanın yanı sıra maliyetleri düşürme ve kaliteyi iyileştirmede de avantajlar sağladığı bilinmektedir (Googerdchian ve ark., 2018). Deneysel veriler denge izoterm modelleri açısından da analiz edilerek değerlendirilmiş ve karşılaştırılmıştır.

\section{MATERYAL VE METOT}

\section{Materyal}

Çalışmada kullanılan aromatik boya Sigma (Aldrich) firmasından temin edilmiştir. Tüm kimyasallar analitik saflıktadır. Çift damıtılmış su ile stok boya çözeltisi $\left(1 \mathrm{~g} \mathrm{~L}^{-1}\right)$ hazırlanmış ve karanlık koşullarda saklanmıştır. Çözeltilerin ilk pH'ları $0.1 \mathrm{~N}$ hidroklorik asit $(\mathrm{HCl})$ ve $0.1 \mathrm{~N}$ sodyum hidroksit $(\mathrm{NaOH})$ çözeltileriyle ayarlanmıştır. Çalışmada kullanılan biyosorbentler Sinop bölgesindeki ormanlık alandan toplanmıştır.

Mantarlar ilk önce distile su ile yıkanmış daha sonra $60{ }^{\circ} \mathrm{C}$ 'de sabit tartıma gelene kadar kurutulmuştur. Kurutulan biyosorbentler Waring marka laboratuvar tipi ögütücüde öğ̈̈tülerek standart bir elek yardımıyla $250 \mu \mathrm{m}$ partikül boyutuna getirilmiştir. Kullanıma hazır olarak uygun bir cam şişede muhafaza edilmiştir. 
Kesikli biyosorpsiyon deneyleri oda sıcaklığında $100 \mathrm{~mL}$ hacimli bir dizi erlenmeyer şişesine 50 $\mathrm{mL}$ boya çözeltisi ve $\left(1 \mathrm{~g} \mathrm{~L}^{-1}\right)$ biyosorbent ilave edilmesi ile gerçekleştirilmiştir. Şişeler $150 \mathrm{rpm}$ hızında periyodik olarak çalkalanmıştır. Biyosorpsiyondan sonra, biyosorbenti çözeltiden ayırmak için, çözelti santrifüjlenmiştir ve boya konsantrasyonu UV-visible spektrofotometre kullanılarak 433 nm'de ölçülmüştür (Zeroual ve ark., 2006). Boya çözeltisi için hazırlanan kalibrasyon eğrisi yardımıyla konsantrasyonlar hesaplanmıştır. Deneysel çalışmanın şematik gösterimi Şekil 1'de verilmiştir. Kirleticinin molekülleri ile biyosorbentin yüzeyi arasındaki etkileşimi tanımlayabilmek için denge verileri Langmuir ve Freundlich izoterm denklemleri kullanılarak MS Excel veri çözücü (solver) ile modellenmiş ve hata değerleri (SSE) programda hesaplanmıştır. Tutarlı ve tekrarlanabilir deneysel veriler elde edebilmek için deneysel çalışmalar iki tekrarlı yapılmış ve ortalama değerler kullanılmıştır.

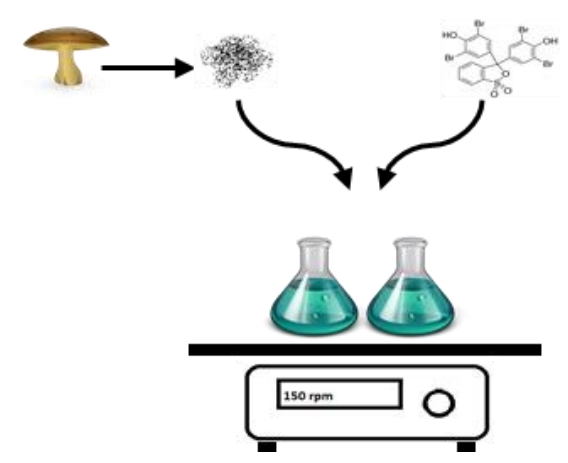

Şekil 1. Deneysel çalışmanın şematik gösterimi

\section{Taguchi Deney Tasarımı}

Taguchi deney tasarım yöntemi en aza indirgenmiş deney sayısı ile optimize edilmiş en uygun parametre kombinasyonlarını belirlemek amaciyla kullanılmaktadır (Googerdchian ve ark., 2018; Taguchi, 1990). Ortogonal dizilerden (OD) yararlanılan tasarım metodunda L9 ( $\left.3^{3}\right)$ OD kullanılmış pH, başlangıç boya konsantrasyonu ve biyosopsiyon zamanı gibi kontrol edilebilir üç önemli faktörün etkisi incelenmiştir. Her faktör için üç farklı seviye belirlenmiştir. Bu belirlemeler yapılırken literatürde daha önce yapılan çalışmalar ve ön deneylerin sonuçları dikkate alınmıştır.

Deney planı Çizelge 1'de sunulmuştur. Bu plan doğrultusunda 9 farklı deney yapılmıştır (Çizelge 2). Tasarım yönteminde değerlendirme ölçütü sinyal/gürültü $(\mathrm{S} / \mathrm{N})$ faktörü oranıdır. Giderim performansı değerlendirilirken hedef maksimum giderim kapasitesi olduğu için "daha büyük daha iyidir" performans istatistiği tercih edilmiştir. Taguchi'nin ve önemli parametrelerin etkisi ve süreçteki katkısı varyans analizi ile değerlendirilmiştir. Tasarım ve değerlendirme çalışmaları Minitab 17 istatistiksel yazılım programı ile yapılmıştır.

Çizelge 1. Tasarımının faktörleri ve seviyeleri

\begin{tabular}{lllll}
\hline Faktör & Birim & $\mathbf{L}_{\mathbf{1}}$ & $\mathbf{L}_{\mathbf{2}}$ & $\mathbf{L} \mathbf{3}$ \\
\hline Başlangıç pH değeri & & 2 & 7 & 12 \\
Boya konsantrasyonu & $\mathrm{mg} \mathrm{L}^{-1}$ & 25 & 50 & 75 \\
Biyosorpsiyon zamanı & $\mathrm{dk}$ & 30 & 150 & 270 \\
\hline
\end{tabular}


Çizelge 2. Taguchi $\mathrm{L}_{9}$ OD deneysel dizaynı

\begin{tabular}{|c|c|c|c|}
\hline Deney no & t (dk) & pH & $\mathrm{C}\left(\mathrm{mg} \mathrm{L}^{-1}\right)$ \\
\hline 1 & 30 & 2 & 25 \\
\hline 2 & 30 & 7 & 50 \\
\hline 3 & 30 & 12 & 75 \\
\hline 4 & 150 & 2 & 50 \\
\hline 5 & 150 & 7 & 75 \\
\hline 6 & 150 & 12 & 25 \\
\hline 7 & 270 & 2 & 75 \\
\hline 8 & 270 & 7 & 25 \\
\hline 9 & 270 & 12 & 50 \\
\hline
\end{tabular}

\section{BULGULAR VE TARTIŞMA}

\section{Taguchi Deney Tasarımı Yöntemi ile Biyosorpsiyon Prosesinin Optimizasyonu}

Biyosorbentlerin boya giderme verimliliği (\%) materyalin Taguchi L9 OD yaklaşımında bir performans parametresi olarak seçilmiş ve elde edilen yanıt verileri $\mathrm{S} / \mathrm{N}$ oranına dönüştürülmüştür (daha büyük daha iyidir). Boya giderimi yüzdeleri (\% giderim) ve $\mathrm{S} / \mathrm{N}$ oranları $F$. fomentarius ve $T$. versicolor için sırasıyla Çizelge 3 ve Çizelge 4'te verilmiştir. Önemli parametrelerin etkisi ve süreçteki katkısı varyans analizi ile değerlendirilmiştir.

Çizelge 3. F. fomentarius ile biyosorpsiyon prosesinde Taguchi $\mathrm{L}_{9}$ OD deneysel tasarımında boya giderimi yüzdeleri ve $\mathrm{S} / \mathrm{N}$ oranları

\begin{tabular}{lccccc}
\hline No & $\mathbf{t}(\mathbf{d k})$ & $\mathbf{p H}$ & $\mathbf{C}\left(\mathbf{m g ~ L}^{-\mathbf{1}}\right)$ & \% giderim & $\mathbf{S} / \mathbf{N}$ \\
\hline 1 & 30 & 2 & 25 & 44.75 & 33.01 \\
2 & 30 & 7 & 50 & 9.56 & 19.61 \\
3 & 30 & 12 & 75 & 1.07 & 0.57 \\
4 & 150 & 2 & 50 & 82.20 & 38.30 \\
5 & 150 & 7 & 75 & 9.71 & 19.75 \\
6 & 150 & 12 & 25 & 3.09 & 9.80 \\
7 & 270 & 2 & 75 & 75.66 & 37.58 \\
8 & 270 & 7 & 25 & 10.6 & 20.50 \\
9 & 270 & 12 & 50 & 5.42 & 14.68 \\
\hline
\end{tabular}

Çizelge 4. T. versicolor ile biyosorpsiyon prosesinde Taguchi $\mathrm{L}_{9} \mathrm{OD}$ deneysel tasarımında boya giderimi yüzdeleri ve $\mathrm{S} / \mathrm{N}$ oranları

\begin{tabular}{lccccc}
\hline No & $\mathbf{t}(\mathbf{d k})$ & $\mathbf{p H}$ & $\mathbf{C}\left(\mathbf{m g ~ L}^{\mathbf{- 1}}\right)$ & \% giderim & $\mathbf{S} / \mathbf{N}$ \\
\hline 1 & 30 & 2 & 25 & 31.65 & 30.01 \\
2 & 30 & 7 & 50 & 6.71 & 16.53 \\
3 & 30 & 12 & 75 & 0.82 & -1.72 \\
4 & 150 & 2 & 50 & 69.28 & 36.81 \\
5 & 150 & 7 & 75 & 8.69 & 18.78 \\
6 & 150 & 12 & 25 & 2.46 & 7.82 \\
7 & 270 & 2 & 75 & 68.82 & 36.75 \\
8 & 270 & 7 & 25 & 1.45 & 3.23 \\
9 & 270 & 12 & 50 & 2.21 & 6.89 \\
\hline
\end{tabular}


Çizelge 5. F. fomentarius ile biyosorpsiyon prosesinde boya gideriminde ANOVA çalışmasının sonuçları

\begin{tabular}{lllllll}
\hline kaynak & df & Seq SS & Adj SS & Adj MS & F & P \\
\hline $\mathrm{t}(\mathrm{dk})$ & 2 & 68.94 & 68.94 & 34.47 & 5.06 & 0.165 \\
$\mathrm{pH}$ & 2 & 1182.33 & 1182.33 & 591.167 & 86.75 & 0.011 \\
$\mathrm{C}$ & 2 & 36.73 & 36.73 & 18.364 & 2.69 & 0.271 \\
hata & 2 & 13.63 & 13.63 & 6.815 & - & - \\
toplam & 8 & 1301.63 & - & - & - & - \\
\hline
\end{tabular}

Çizelge 6. T. versicolor ile biyosorpsiyon prosesinde boya gideriminde ANOVA çalışmasının sonuçları

\begin{tabular}{lllllll}
\hline Kaynak & df & Seq SS & Adj SS & Adj MS & F & p \\
\hline $\mathrm{t}(\mathrm{dk})$ & 2 & 16.33 & 16.33 & 8.163 & 0.23 & 0.811 \\
$\mathrm{pH}$ & 2 & 1949.68 & 1949.68 & 974.842 & 27.83 & 0.035 \\
$\mathrm{C}$ & 2 & 412.23 & 412.23 & 206.115 & 5.88 & 0.145 \\
Hata & 2 & 70.06 & 70.06 & 35.031 & - & - \\
Toplam & 8 & 2448.30 & - & - & - & - \\
\hline
\end{tabular}

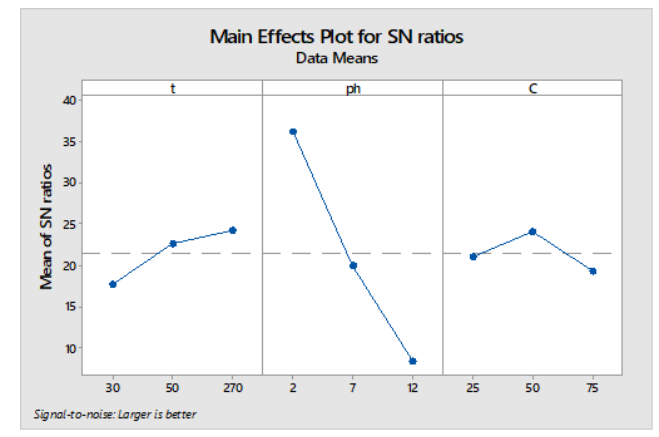

Şekil 2. F. fomentarius ile biyosorpsiyon prosesi optimizasyonunda parametrelerin etkileri

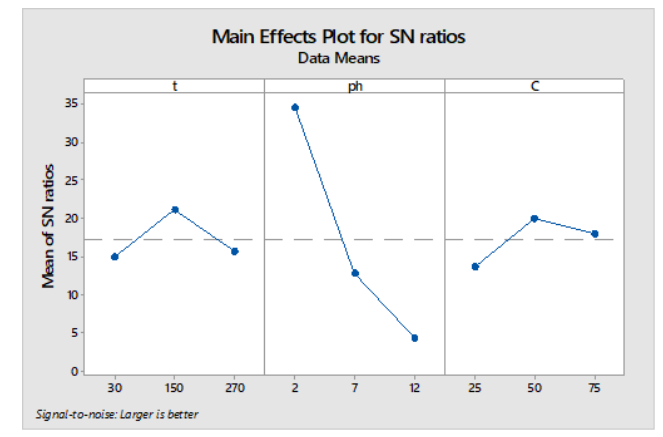

Şekil 3. T. versicolor ile biyosorpsiyon prosesi optimizasyonunda parametrelerin etkileri

En yüksek yanıt değeri her değişkenin en iyi seviyesini belirlemiştir ve çalışılan parametreler arasında optimum olarak yorumlanmış ve seçilmiştir. Şekil 2 ve 3 incelendiğinde F.fomentarius için zamanda en iyi yanıt 3. seviye olan $270 \mathrm{dk}$, başlangıç $\mathrm{pH}$ değeri için 1 . seviye olan 2 ve başlangıç boya konsantrasyonu için 2. seviye olan $50 \mathrm{mg} \mathrm{L}^{-1}$ belirlenmiştir. T. versicolor için zamanda en iyi yanıt 2 . seviye olan $150 \mathrm{dk}$, başlangıç pH değeri için 1. seviye olan 2 ve başlangıç boya konsantrasyonu için 2 . 
seviye olan $50 \mathrm{mg} \mathrm{L}^{-1}$ belirlenmiştir. Çizelge 5 ve 6'da verilen ANOVA sonuçlarından hesaplanan F ve $\mathrm{p}$ değerleri doğrultusunda başlangıç $\mathrm{pH}$ değerlerinin ( $\mathrm{p}<0.05$ olduğu için) biyosorpsiyonda istatistiksel olarak anlamlı ve etkili bir parametre olduğu söylenebilir. Analiz sonucunda $F$. fomentarius ile biyosorpsiyonda $270 \mathrm{dk}$ sonunda, başlangıç $\mathrm{pH}$ değeri 2 ve $50 \mathrm{mg} \mathrm{L}^{-1}$ başlangıç boya konsantrasyonu koşullarında \%76.7 giderim, $41.68(\mathrm{~S} / \mathrm{N})$ oranı ve $T$. versicolor ile biyosorpsiyonda $150 \mathrm{dk}$ sonunda, başlangıç pH değeri 2 ve $50 \mathrm{mg} \mathrm{L}^{-1}$ başlangıç boya konsantrasyonu koşullarında \%66.77 giderim 41.27 $(\mathrm{S} / \mathrm{N})$ oranı belirlenmiştir. Belirlenen koşullar için yapılan doğrulama deneylerinde $F$. fomentarius ile biyosorpsiyonda $\% 78.34$ boya giderimi ve $T$. versicolor ile biyosorpsiyonda $\% 69.28$ boya giderimi edilmiştir. Elde edilen değerlerin birbirleri ile tutarlı olması modelin parametrelerin etkisini açıklamada oldukça başarılı olduğunun göstergesidir.

Her iki biyosorbent için de düşük $\mathrm{pH}$ değerinde çok daha iyi sonuçlar elde edilebileceği görülmüştür. Boyanın kimyasal yapısına da bağlı olarak çözelti pH'sı düştüğünde $\mathrm{H}^{+}$iyonları artışıyla boyanın adsorplanma kabiliyetinde artış olmuştur. Benzer bulgulardan literatürde bahsedilmektedir. Bromfenol Mavisi giderimi için mantar biyokütlesi ile adsorpsiyonda ve grafen oksit fonksiyonlu manyetik kitosan kompozit ile adsorpsiyonda maksimum giderimler asidik pH (2) değerinde olmuştur (Zeroual ve ark., 2006; Sohni ve ark., 2018). Boyanın asidik pH'da alımının artması, biyosorbent ve boya arasındaki elektrostatik etkileşimler açısından açıklanabilir. Azalan $\mathrm{pH}$ ile biyosorbentte fazlaca zayıf baz grubu protonlanır ve net bir pozitif yük elde edilir. Bu yüklü bölgeler, Bromfenol Mavisi boyası gibi anyonik gruplara bağlanmak için kullanılabilir hale gelir. Hidrojen iyonları ayrıca biyosorbent ile boya molekülü arasında bir köprü ligandı olarak işlev görür (Zeroual ve ark., 2006). Mantar hücre duvarı, boya moleküllerini bağlayabilen çeşitli fonksiyonel gruplarla (amino, karboksil, tiol ve fosfat grupları gibi) polisakkaritler (kitin ve kitosan), proteinler, lipitler ve melaninden oluşmaktadır. Ayrıca mantar biyokütlesi pürüzlü ve gözenekli bir yüzeye sahiptir. Bu yüzey özelliği, toplam yüzey alanında artış sağlayan bir faktör olarak düşünülmektedir (Bayramoğlu ve Arıca, 2007).

\section{Biyosorpsiyon Prosesinin İzoterm Modellemesi}

Biyosorpsiyon sisteminin denge verileri Freundlich (1906) ve Langmuir (1918) izotermleri kullanılarak modellenmiştir. Deneyler, Taguchi tasarımı kullanılarak belirlenen parametrelerin optimum seviyesi kullanılarak gerçekleştirilmiştir. F. fomentarius için $270 \mathrm{dk}$ ve başlangıç pH değeri 2 ile $T$. versicolor için $150 \mathrm{dk}$ ve başlangıç $\mathrm{pH}$ değeri 2 olarak başlangıç konsantrasyon 25, 50 ve $75 \mathrm{mg} \mathrm{L}^{-1}$ olarak değişen oranlarda çalışılmıştır.

Freundlich

$$
q e=K_{F} C e^{1 / n F}
$$

Langmuir

$$
q e=\frac{q m K_{L} C e}{1+K_{L} C_{e}}
$$

qe ve qm denge ve maksimum biyosorpsiyon kapasiteleri $\left(\mathrm{mg} \mathrm{g}^{-1}\right), \mathrm{K}_{\mathrm{F}}, \mathrm{n}_{\mathrm{F}}$ ve $\mathrm{K}_{\mathrm{L}}$ Freundlich ve Langmuir model sabitleri ve $\mathrm{Ce}\left(\mathrm{mg} \mathrm{L}^{-1}\right)$ kirletici konsantrasyonudur. Lineer olmayan model denklemleriyle hesaplanan biyosorpsiyon kapasiteleri Çizelge 7'de verilmiştir. En küçük hata değeri ve en yüksek $\mathrm{R}^{2}$ değeri en uygun modeli belirlemiştir. Her iki modelde de yüksek $\mathrm{R}^{2}$ değeri ile uyum elde edilmiştir. F. fomentarius ile yapılan deneylerde en iyi model uyumu Freundlich izoterminde sağlanırken T. versicolor ile yapılan deneylerde en iyi uyum en düşük hata değeri ile Langmuir izotermi ile sağlanmıştır. Langmuir denklemiyle maksimum biyosorpsiyon kapasitesi $F$. fomentarius için $182.23 \mathrm{mg}$ $\mathrm{g}^{-1}$, T. versicolor için $142.33 \mathrm{mg} \mathrm{g}^{-1}$ olarak hesaplanmıştır. Langmuir ve Freundlich lineer olmayan izoterm denklemleri ile modelleme uyumu Şekil 4'te gösterilmiştir. 
Çizelge 7. Model parametreleri

\begin{tabular}{lll}
\hline Model parametreleri & $\boldsymbol{F}$. fomentarius & T. versicolor \\
\hline Freundlich izoterm modeli & & \\
$\mathrm{K}_{\mathrm{F}}\left(\mathrm{mg}^{1-1 / \mathrm{n}} \mathrm{L}^{1 / \mathrm{n}} \mathrm{g}^{-1}\right)$ & 5.94 & 4.24 \\
$1 / \mathrm{n}_{\mathrm{F}}$ & 0.779 & 0.761 \\
Hata $(\mathrm{SSE})$ & 1.67 & 1.026 \\
$\mathrm{R}^{2}$ & 0.9975 & 0.9999 \\
Langmuir izoterm modeli & & \\
qm $\left(\mathrm{mg} \mathrm{g}^{-1}\right)$ & 182.23 & 142.33 \\
$\mathrm{~K}_{\mathrm{L}}(\mathrm{L} \mathrm{mg}$ & 0.021 \\
$\mathrm{R}_{\mathrm{L}}$ & 0.0249 & $0.39-0.66)$ \\
Hata $(\mathrm{SSE})$ & $(0.35-0.62)$ & 0.008 \\
$\mathrm{R}^{2}$ & 5.26 & 0.9971 \\
\hline
\end{tabular}
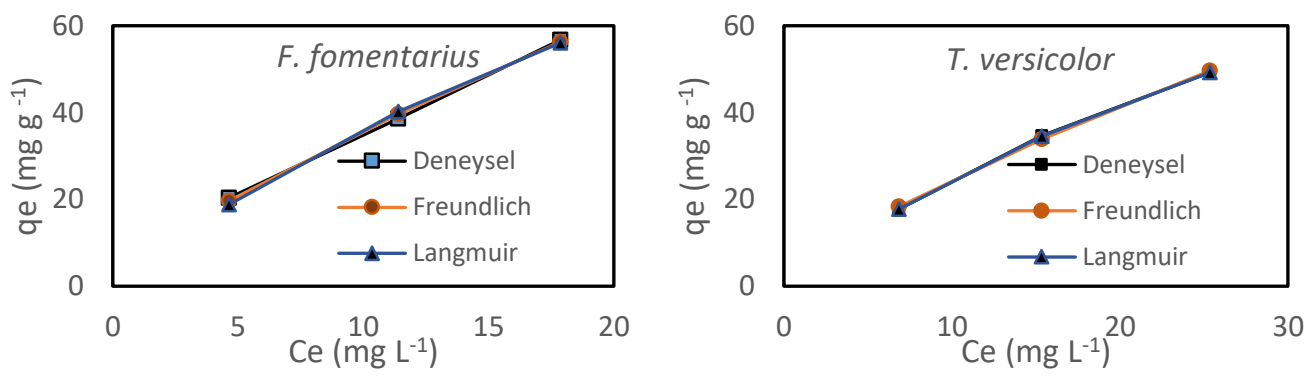

Şekil 4. Langmuir ve Freundlich lineer olmayan izoterm denklemleri ile modelleme

\section{Karşılaştırma Çalışması}

Literatürde yer alan çeşitli adsorbanların Bromfenol Mavisi giderim kapasitelerinin karşılaştırılması Çizelge 8'de verilmiştir. Ayrıca çalışmada kullanılan biyosorbentlerin doğrusal olmayan Langmuir model denklemiyle hesaplanan maksimum giderim kapasiteleri de hesaplanarak çizelgede sunulmuştur. Her iki biyosorbent de Bromfenol Mavisi gideriminde literatürdeki birçok adsorbana göre yüksek bir adsorplama kabiliyeti sergilemiştir.

Çizelge 8. Çeşitli adsorbanların Bromfenol Mavisi giderme kapasitelerinin karşılaştırılması

\begin{tabular}{lll}
\hline$(\mathbf{q} \max )\left(\mathbf{m g ~ g}^{-1}\right)$ & Adsorbent & Referans \\
\hline 30.32 & Nano CuO & Rashad ve Al-Aoh 2019 \\
22.72 & $\alpha$-chitin & Dhananasekaran ve ark.,2016 \\
1.89 & Aktif karbon & Dada ve ark., 2012 \\
182.23 & Fomes fomentarius & Bu çalışma \\
142.33 & Trametes versicolor & Bu çalışma \\
\hline
\end{tabular}

SONUÇ

$\mathrm{Bu}$ çalışmada kolay erişilebilir ve çevre dostu sorbentler olan $F$. fomentarius ve $T$. versicolor kullanılarak sulu çözeltiden Bromfenol Mavisi giderimi çalışılmıştır. Biyosorpsiyon için optimum koşullar Taguchi yöntemi ile tasarlanmış ve deneysel olarak belirlenmiştir. Analiz sonucunda $F$. fomentarius ile $270 \mathrm{dk}$ sonunda, başlangıç $\mathrm{pH}$ değeri 2 ve başlangıç boya konsantrasyonu $50 \mathrm{mg} \mathrm{L}^{-1}$ koşullarında \%76.7 giderim verimi, $41.68(\mathrm{~S} / \mathrm{N})$ oranı ve T. versicolor ile $150 \mathrm{dk}$ sonunda, başlangıç $\mathrm{pH}$ değeri 2 ve başlangıç boya konsantrasyonu $50 \mathrm{mg} \mathrm{L}^{-1}$ koşullarında \%66.77 giderim verimi, $41.27(\mathrm{~S} / \mathrm{N})$ oranı belirlenmiştir. Belirlenen koşullar için yapılan doğrulama deneylerinde F.fomentarius ile 
biyosorpsiyonda $\% 78.34$ boya giderim verimi ve $T$. versicolor ile biyosorpsiyonda \%69.28 boya giderim verimi elde edilmiştir. Denge izotermleri Langmuir ve Freundlich izoterm denklemleri kullanılarak modellenmiştir. $F$. fomentarius ile yapılan deneyler Freundlich izotermi ile $T$. versicolor ile yapılan deneyler Langmuir izotermi ile daha iyi uyum sağlamıştır. Elde edilen sonuçlar ışığında deneysel tahminler ve doğrulama sonuçları birbirine çok yakın değerler olduğu için Taguchi (L9 (3³) OD) deney tasarımının boya endüstrisi atıksularının arıtımında biyosorpsiyon prosesi tasarımında kullanılması önerilmektedir. Bununla birlikte Fomes fomentarius ve Trametes versicolor'un literatürdeki çoğu adsorbente kıyasla oldukça yüksek boya giderim kapasitesi sergilediği belirlenmiştir.

\section{Çıkar Çatışması}

Makale yazarları aralarında herhangi bir çıkar çatışması olmadığını beyan ederler.

\section{Yazar Katkısı}

Yazarlar makaleye eşit oranda katkı sağlamış olduklarını beyan eder.

\section{KAYNAKLAR}

Bayramoğlu G, Arıca MY, 2007. Biosorption of benzidine based textile dyes Direct Blue 1 and Direct Red 128 using native and heat-treated biomass of Trametes versicolor. Journal of Hazardous Materials, 143, 1-2, 135-143.

Dada AO, Inyinbor AA, Oluyori AP, 2012. Comparative adsorption of dyes unto activated carbon prepared from maize stems and sugar cane stems. Journal of Applied Chemistry, 2: 38-43.

Dhananasekaran S, Palanivel R, Pappu S, 2016. Adsorption of methylene blue, bromophenol blue, and coomassie brilliant blue by a-chitin nanoparticles. Journal of advanced research, 7: 113-124.

El-Gamal SMA, Amin MS, Ahmed MA, 2015. Removal of methyl orange and bromophenol blue dyes from aqueous solution using Sorel's cement nanoparticles. Journal of environmental chemical engineering, 3(3): 1702-1712.

Freundlich H, 1906. Over the adsorption in solution. Zeitschrift für physikalische Chemie. 57: 385-470.

Googerdchian F, Moheb A, Emadi R, Asgari M, 2018. Optimization of $\mathrm{Pb}$ (II) ions adsorption on nanohydroxyapatite adsorbents by applying Taguchi method. Journal of hazardous materials, 349: 186194.

Katheresan V, Kansedo J, Lau SY, 2018. Efficiency of various recent wastewater dye removal methods: $a$ review. Journal of environmental chemical engineering, 6(4): 4676-4697.

Langmuir I, 1918. The adsorption of gases on plane surfaces of glass, mica and platinum. Journal of the American Chemical society. 40(9): 1361-1403.

Maurya NS, Mittal AK, Cornel P, Rother E, 2006. Biosorption of dyes using dead macro fungi: effect of dye structure, ionic strength and $\mathrm{pH}$. Bioresource technology, 97(3): 512-521.

Rashad M, Al-Aoh, HA, 2019. Promising adsorption studies of bromophenol blue using copper oxide nanoparticles. Desalination and Water Treatment, 139: 360-368.

Seow TW, Lim CK, 2016. Removal of dye by adsorption: a review. International Journal of Applied Engineering Research, 11(4): 2675-2679.

Sohni S, Gul K, Ahmad F, Ahmad I, Khan A, Khan N, Bahadar Khan S, 2018. Highly efficient removal of acid red-17 and bromophenol blue dyes from industrial wastewater using graphene oxide functionalized magnetic chitosan composite. Polymer Composites, 39(9): 3317-3328.

Subbaiah MV, Yuvaraja G, Vijaya Y, Krishnaiah A, 2011. Equilibrium, kinetic and thermodynamic studies on biosorption of $\mathrm{Pb}$ (II) and $\mathrm{Cd}$ (II) from aqueous solution by fungus (Trametes versicolor) biomass. Journal of the Taiwan Institute of Chemical Engineers, 42(6): 965-971.

Taguchi G, 1990. Introduction to Quality Engineering. McGraw-Hill, New York, USA. 
Zare EN, Motahari A, Sillanpää M, 2018. Nanoadsorbents based on conducting polymer nanocomposites with main focus on polyaniline and its derivatives for removal of heavy metal ions/dyes: a review. Environmental research, 162: 173-195. 3.

Zeroual Y, Kim BS, Kim CS, Blaghen M, Lee KM, 2006. Biosorption of bromophenol blue from aqueous solutions by Rhizopus stolonifer biomass. Water, air, and soil pollution, 177(1-4): 135-146. 